\title{
Smart Cities and Digitized Urban Management
}

\author{
Tobias Brandt • Wolf Ketter • Lutz M. Kolbe • \\ Dirk Neumann $\cdot$ Richard T. Watson
}

Published online: 3 April 2018

(C) Springer Fachmedien Wiesbaden GmbH, part of Springer Nature 2018

\section{Background}

By 2050, two-thirds of the world's population is expected to reside in cities and urban agglomerations (UN Department of Economic and Social Affairs 2014). Cities have always showcased the best and the worst aspects of humanity - gleaming skyscrapers, art, and inventiveness on the one hand; slums, crime, and abject poverty on the other. Such challenges, which cities already face, will be further amplified by increasing urbanization, and it will be coastal

Dr. T. Brandt $(\bowtie) \cdot$ Prof. W. Ketter Ph.D.

Rotterdam School of Management, Erasmus University

Rotterdam, PO Box 1738, 3000 DR Rotterdam, The Netherlands

e-mail: brandt@rsm.nl

Prof. W. Ketter Ph.D.

e-mail: ketter@wiso.uni-koeln.de

Prof. W. Ketter Ph.D.

Faculty of Management, Economics, and Social Sciences, University of Cologne, Pohligstr. 1, 50969 Cologne, Germany

Prof. W. Ketter Ph.D.

Institute of Energy Economics, Vogelsanger Straße 321a,

50827 Cologne, Germany

Prof. Dr. L. M. Kolbe

University of Göttingen, Platz der Göttinger Sieben 5, Göttingen, Germany

e-mail: lutz.kolbe@wiwi.uni-goettingen.de

Prof. Dr. D. Neumann

University of Freiburg, Platz der Alten Synagoge,

79098 Freiburg, Germany

e-mail: dirk.neumann@is.uni-freiburg.de

Prof. R. T. Watson Ph.D.

Department of Management Information Systems, Terry College, University of Georgia, Athens, GA 30602-6273, USA

e-mail: rwatson@terry.uga.edu cities in particular that bear the brunt of the global threat of climate change. Not without reason is the quest for "Sustainable Cities and Communities" one of the UN's explicit sustainable development goals (United Nations 2015).

To reach this goal, city governments and urban businesses are increasingly turning to information technology and systems as a way to make cities more efficient, sustainable, and resilient. Around the world, various initiatives seek to bring stakeholders together and leverage digital means for improving urban life. Examples include the European Union's Smart Cities and Communities funding line (European Commission 2018), the Rockefeller Foundation's 100 Resilient Cities initiative (100 Resilient Cities 2018), or the Smart Nation Singapore project (Smart Nation and Digital Government Office 2018). Being involved in several of these or similar efforts, when talking to city officials we frequently encounter two issues that are perceived as fundamental for a successful transition to a smart, sustainable, and resilient city. The first relates to a solid IT infrastructure, be it city-wide $\mathrm{Wi}-\mathrm{Fi}$, broadband Internet access, or low-power networks to connect smart objects. These and similar technologies are often considered to be a necessary foundation to enable the emergence of smart services within the city. The second issue shifts the focus away from the technology to the people within the city, arguing that smart cities should first and foremost be human(e) cities. Technology should be employed to benefit the people within the city and be designed with the needs of the population in mind.

The analysis of the design and use of information technology and systems in its organizational and societal context is central to the Information Systems discipline. Consequently, the digital transformation of cities should be a vibrant research area within our community, allowing scholars to study the impact of IS-induced change at a scale 
that is often far grander than what can be observed within a more traditional enterprise-centric focus. While we are aware that many of our colleagues are working with city administrations and other relevant stakeholders on smart city projects, these efforts were slow to manifest in the publication outlets of our discipline. However, over the past years this has been changing, with panels and tracks focused on smart cities and digitized urban management appearing in leading IS conferences, including ICIS, HICSS, ECIS, and AMCIS. This special issue further advances this process by providing a journal platform for smart city research.

\section{Contents of this Special Issue}

The idea for this special issue originated at ICIS 2015 in Fort Worth and it was subsequently advertised at AMCIS 2016, ICIS 2016, and the Erasmus Energy Forum 2017. We received 17 submissions, four of which were eventually accepted after a rigorous and competitive review process. In addition to their academic merit, we believe that each of these papers illustrates the strength of our discipline in analyzing the links and interdependencies between technology and human stakeholders in a smart city context.

The first paper, "Smart Cities: A Review and Analysis of Stakeholders' Literature" by Mauricio Marrone and Mara Hammerle, investigates how the perception of and the emphasis on different smart city technologies vary between stakeholder groups. By analyzing publication outlets that are distinct to each group, they find that issues relevant to citizens are not always shared by businesses, governments, and academics. Their research emphasizes the necessity to design smart city projects and services with the needs and concerns of citizens in mind.

The second paper, "Exploring the Motives of Citizen Reporting Engagement: Self-Concern and Other-Orientation" by Gabriel Abu-Tayeh, Oliver Neumann, and Matthias Stuermer, builds upon that notion by analyzing an app that actively leverages citizen feedback to identify infrastructure damages and other issues within the city. The authors combine survey responses with activity data from the app to assess the degree to which self-concern and other-orientation determine user engagement.

Incentivizing people to behave in a more sustainable manner through IS feedback is the focus of the third paper in this special issue, "Sharing Yet Caring - Mitigating Moral Hazard in Access-Based Consumption through ISEnabled Value Co-Capturing with Consumers" by Björn Hildebrandt, Andre Hanelt, and Sebastian Firk. The authors study an urban carsharing service and analyze how feedback mechanisms can be used to encourage more considerate behavior when using shared resources in access-based consumptions services.

The fourth and final research paper adds a distinctly different perspective to the special issue. In "Do Not Forget About Smart Towns - How to Bring Customized Digital Innovation to Rural Areas", Sabiölla Hosseini, Leonhard Frank, Gilbert Fridgen, and Sebastian Heger caution against the exclusive focus on smart cities, arguing that the digital transformation also profoundly affects small towns and rural areas. Analyzing the case of a small tourist town, they illustrate how rural areas differ from cities with respect to scale advantages on the one hand and stakeholder involvement on the other.

The special issue is concluded by an interview with Dr. David Prendergast, who has researched topics surrounding information technology, social relationships, and ageing for the past two decades. Until recently, he has worked for Intel, directing Urban Living Labs and Internet-of-Things testbeds in London, San Jose, and Dublin.

\section{Outlook}

The special issue brings together research on various domains in which information systems change the way citizens experience the city. Nevertheless, these are just few of all potential applications. Digitization can transform any of a city's subsystems - such as energy infrastructures, urban transportation, or waste disposal - but also link across systems to establish integrated neighborhoods and communities. Information technology can also further broaden the digital divide, be it between young and old people or urban and rural areas. Hence, research and critical reflection is clearly necessary and we hope that this special issue is just one step towards a larger presence of research on the digital transformation of cities and communities in IS journals.

Concluding, we would like to express our gratitude to the authors who submitted their work to this special issue, as well as to the reviewers who provided timely and constructive feedback. We also thank the BISE editorial staff for their technical and administrative support and Martin Bichler for advice and guidance.

\section{References}

European Commission (2018) H2020 energy: smart cities and communities. https://ec.europa.eu/inea/en/horizon-2020/h2020energy/projects-by-field/smart-cities-and-communities. Accessed 31 Jan 2018

Resilient Cities (2018) About us. http://www.100resilientcities.org/ about-us/. Accessed 31 Jan 2018 
Smart Nation and Digital Government Office (2018) Smart nation Singapore. https://www.smartnation.sg/. Accessed 31 Jan 2018

UN Department of Economic and Social Affairs (2014) World urbanization prospects: the 2014 revision, highlights. United Nations, New York
United Nations (2015) Sustainable development goals. http://www. un.org/sustainabledevelopment/sustainable-development-goals/. Accessed 31 Jan 2018 